John M. Riebold (York University)

Creak in the Rain: Phonation in Oregon English

The Pacific Northwest - typically defined as Oregon, Washington, Idaho, and occasionally British Columbia - is a young region in comparison with most of the rest of North America, being one of the last regions settled during the westward expansion of the $19^{\text {th }}$ century. Major migration to Oregon began around 1840, and it was officially inducted into the union in 1859, making the state just over 150 years old. Immigration to Oregon and the Pacific Northwest came from all across the US and Canada, but chiefly from the US Midlands. The young age of the region means that there has been less time for a cohesive set of dialect features to emerge from the linguistic chaos following mass migration, however there are some indications that English in the Northwest does have some unique characteristics.

Pacific Northwestern English forms part of the "third dialect" of English. The Atlas of North American English characterizes Pacific Northwestern English as having an absence of Canadian Raising, the presence of the low-back merger, the absence of (strongly) fronted /ow/, and absence of glide deletion in /ay/ (Labov, Ash, \& Boberg 2006). Unlike many other Englishspeaking dialect areas, English in the Pacific Northwest has seen relatively little research prior to the last decade (see Foster \& Hoffman 1966, Reed 1961, and Reed 1983), which is perhaps due in part to the perception (both by outsiders and natives of the region) that Pacific Northwest English is neutral, that is, very close to Standard North American English. Most natives of the Pacific Northwest insist that they don't speak with any kind of accent, although this is not true of the third dialect as a whole, as shown by the existence of stereotypical Californian accents (e.g. the "surfer dude", the "valley girl", etc) which most US Americans can perform on cue. There are no such (linguistic) stereotypes about the Northwest, however as linguists we know that everyone has an "accent", so to speak, and therefore the question is: what are its features? Recent work which has been done in the area suggests some emerging features which might be characteristic of the dialect. Findings include participation in the Canadian/Californian shift (Conn 2002), centralization of front and back vowels (Conn 2002, Ingle et al. 2005, Riebold 2009, Ward 2003), raising of /æ, e:, $\varepsilon /$ before /g/ (Wassink, Squizzero, Scanlon, Schirra, Conn 2009), lexical differences (e.g. go to the coast, full on) (Conn 2006), and some Midland dialect features such as positive anymore (Conn personal communication, February 9, 2009). Another frequently reported finding is the use of creaky voice among Northwesterners (Conn, personal communication, February 9, 2009, Ingle et al. 2005, Ward 2003), particularly among women.

Creaky voice (variously: creak, glottal/vocal fry, pulse phonation, laryngealization) is a type of phonation involving a relaxing or bunching of the vocal folds, characterized by a low fundamental frequency and a slow rate of vibration (Laver 1994), often compared to the sound made by a creaky door, or by "a stick being run along railings" (Catford 1964 in Laver 1994). Although this paper does not focus on the articulatory and phonetic details of creaky voice, it is informed by previous research into the phenomenon. Much of the work that has been done on creaky voice suggests that an $\mathrm{F}_{0}$ of between $20-70 \mathrm{~Hz}$ (well below typical modal ranges) as well as irregular, separately-resolvable (both auditorily and under instrumental analysis) glottal pulses are crucial to the production and perception of creaky voice (Henton \& Bladon 1988, Laver 1994). There are many physiological and prosodic factors which can condition the non-linguistic occurrence of creaky voice, such as exhaustion or drowsiness, vocal fold elasticity, glottal segments, and very low-pitched segments of speech (such as at the ends of utterances) (Henton \& Bladon 1988). Creaky voice can also be idiolectal, as some people are simply persistent 
“creakers” (Henton \& Bladon 1988). It is important to note that because of the many causes of creaky voice, creak should, in theory, be present in everyone's speech under the right circumstances, however this does not preclude speakers from deploying it linguistically. Linguistically-conditioned uses of creaky voice are found in many languages, such as Vietnamese and Danish, where creaky voice is lexically contrastive (Laver 1994), and Finnish, where it forms part of the Finnish turn-taking system (Ogden 2001).

Presently, research into the use of creaky voice in dialects of English is limited, with most of the work having been done on regional dialects in England, such as Henton \& Bladon 1988, which was an investigation into the frequency, but not the function, of creaky voice in England. Henton \& Bladon used the Oxford Corpus, which contained 40 speakers of two dialects of English: Received Pronunciation and what they called Modified Northern. They found that the utterance final syllable position had a strong statistically significant effect on the usage of creaky voice (1988). Laver's Principles of Phonetics also treats creaky voice, mentioning that it forms part of the turn-taking system of some English dialects, and that it is sometimes "emblematic of bored resignation" (1994). Unfortunately, neither of these assertions is supported by citations or direct evidence, and I found no other mention of this in the literature. Finally, it has also been shown that creak can form part of a person's stylistic repertoire, where it is used to effectively widen a speaker's $F_{0}$ range (Podesva 2007). If creaky voice is indeed more common in the speech of Pacific Northwesterners, then it is possible that it is serving a linguistic function in this variety.

Despite the reports that creaky voice is used frequently by Pacific Northwesterners, its use in this dialect has never been investigated either qualitatively or quantitatively. This paper is an analysis of the use of creaky voice in the speech of four Oregonians from the town of Corvallis in the Willamette Valley, about two hours south of Portland, and about one hour from the coast. Of the speakers, three are males, and all are between 22-24 years old, white, middle class, and university-educated. The uniformity in speaker selection is intended to maximize the relevance of any results obtained from this small-scale study. The data come from two interviews, each approximately one hour long, with two speakers, which were structured as informal conversations between the two speakers. To that end, only one or two initial prompts were given, after which a more or less natural flow of conversation commenced. The interviews were recorded digitally using a laptop and a vocal microphone, and were transcribed using ELAN annotation software, with a separate tier marking each speaker's use of creaky voice. All tokens were identified impressionistically, coded, then spot-checked and analyzed in Praat. For the purposes of this paper, a token was defined as a single unbroken length of creaky voice speech, which was motivated by the observation that, in this data, creaky voice tends to span multiple syllables and/or words when it occurs.

Analysis of the two hours of recorded speech yielded 455 tokens of creaky voice, all of which were taken from natural speech; no word-lists or elicitations were used. The tokens were coded for clausal-, utterance-, and turn position (initial, medial, final, entire, multiple), and for the presence of adjacency pairs, discourse markers, and fillers. The tokens were analyzed using basic statistical methods (e.g. percentages, totals, ratios), which revealed that creaky voice shows up in the full range of positions, and tends to persist, with an average token length of 2.38 words (many tokens are 5+ words long). Looking at the totals for each environment however, it seems that the clause-final environment is the best predictor of creaky voice, with the majority (63.81\%) of the tokens occurring in this position. Support for the assertion that this is an important factor comes from the fact that there is a significant degree of homogeneity in the four 
speakers' totals for clause-final, with totals ranging from $56.25 \%$ to $69.33 \%$. Utterance-final is a close second in terms of the amount of tokens it accounts for $(56.48 \%)$ however because the decision to divide a given segment of speech into one or more utterances is subjective, and because $77.81 \%$ of tokens marked as clause final are also utterance final, this may not be a significant factor, and may only be an indication that clause- and utterance ends tend to coincide. Turn-medial accounted for the most tokens within the turn position group, with $58.24 \%$ of the tokens occurring in this environment, however this is an unlikely trigger environment. Other factors such as adjacency pairs, fillers, and discourse markers accounted for very small fractions of the data, and are therefore unlikely to be significant.

Although there is no clear cut explanation for creaky voice it does seem clear that something is going on, based on the uniformity of token distributions and the fact that there are some good predictors of creak. Creaky voice does not appear to be purely physiologicallyconditioned, nor purely prosodically-conditioned, as that would predict utterance-final creak, but not clause-final creak, which is the better predictor in this data. Fatigue would predict a steadily increasing amount of creaky voice during the course of the interview, which is not observed, and would not be able to explain the fact that creaky voice often ceases at clause boundaries, which is observed. Clause-final on the other hand is supported by inter-speaker homogeneity in token distribution, and accounts for the most tokens overall. It is possible, then, that the clause-final occurrence of creaky voice is due to steeper drops in pitch at the ends of Oregonian sentences, or that creaky voice is used to signal the ends of clauses much like short pauses are used to demarcate subordinate clauses. Another possibility which falls out from the data is that creak is being used discursively to signal extended turns-at-talk, motivated by the fact that the majority of the tokens are in turn-medial position (58.24\%), and the observation that very few tokens occur in adjacency pairs, which are typically turn-boundaries. In fact, most creaky voice occurs at the ends of discourse units, where interruptions are more likely to occur. Under this explanation then, creaky voice would be a way for a speaker to maintain the floor despite the initiation of word-search, or a slower rate of speech, both of which might be seen as opportunities for another speaker to begin a turn of their own.

Although this study is far from conclusive given its small scale, it contributes to the fields of dialectology and conversation analysis, as well as to the growing body of literature surrounding Pacific Northwestern and Oregonian English. Additionally, research into phonation expands our understanding of the ways in which different phonations are used crosslinguistically, as phonation is sometimes overlooked in languages where it is not lexically contrastive, and the challenge that this topic presents to researchers is that of separating the linguistic use of creak from the "noise", that is, the non-linguistic use of creaky voice triggered by other factors. Naturally though, this isn't the end of the story. This project represents merely the first in-road into the study of phonation in the Northwest, and the intention is that more follow, in order to further our knowledge of the dialect, and of phonation in general.

\section{Abridged References}

Conn, J. (2002). It's not all Rain and Coffee: An Investigation into the Western Dialect of Portland, Oregon. Paper presented at New Ways of Analyzing Variation 31, Stanford, California, USA. 
Conn, J. (2006). Dialects in the Mist (Portland, OR). In Wolfram, W., \& Ward, B., (Eds.), American Voices: How Dialects Differ from Coast to Coast (149-155). Malden, MA: Blackwell.

Foster, D. W., \& Hoffman, R. J., (1966). Some Observations on the Vowels of Pacific Northwest English (Seattle Area). American Speech, 41 (2), 119-122.

Hartley, L. (1999). A View from the West: Perceptions of U.S. Dialects by Oregon Residents. In D. R. Preston (Ed.), Handbook of Perceptual Dialectology Volume 1 (315-332). Amsterdam; Philadelphia: John Benjamins Publishing Company.

Henton, C., \& Bladon, A. (1988). Creak as a Sociophonetic Marker. In V. Fromkin, L. M. Hyman, \& C. N. Li (Eds.), Language, speech, and mind: Studies in honour of Victoria A. Fromkin (3-29). London; New York: Routledge.

Ingle, J. K., Wright, R. A., \& Wassink, A. B. (2005). Pacific Northwest Vowels: A Seattle Neighborhood Dialect Study. Lay Language Paper presented at the 149th meeting of the Acoustical Society of America, Vancouver, British Columbia, Canada. http://www.aip.org/149th/ingle.html

Labov, W., Ash, S., \& Boberg, C. (2006). Atlas of North American English. Berlin: Mouton de Gruyter.

Laver, J. (1994). Principles of Phonetics. Cambridge: Cambridge University Press.

Ogden, R. (2001). Turn Transition, Creak and Glottal Stop in Finnish Talk-in-Interaction. Journal of the International Phonetic Association, 31 (1), 139-152.

Podesva, R. (2007). Phonation Type as a Stylistic Variable: The Use of Falsetto in Constructing a Persona. Journal of Sociolinguistics, 11 (4), 478-504.

Portland Dialect Study (2003). http://www.pds.pdx.edu/

Reed, C. E. (1961). The Pronunciation of English in the Pacific Northwest. Language, 37 (4), 559-564.

(1983). Linguistic Backpacking in the Pacific Northwest. Journal of English Linguistics, 16, 78-80.

Riebold, J. (2009). Local Spoken Here: English in Oregon. Unpublished manuscript.

Wassink, A. B., \& Conn, J. (2009). The Pacific Northwest English Project. http://www.artsci.washington.edu/nwenglish/index.asp

Ward, M. (2003). Portland Dialect Study: The Fronting of /ow, $u$, and uw/ in Portland, Oregon. Retrieved from the Portland Dialect Study website: http://www.pds.pdx.edu/ 